\title{
Em defesa dos fumantes e dos não fumantes
}

\author{
In defense of smokers and nonsmokers
}

\author{
Luiz Antonio Teixeira \\ Pesquisador da Casa de Oswaldo Cruz/Fundação Oswaldo Cruz. \\ teixeira@coc.fiocruz.br
}

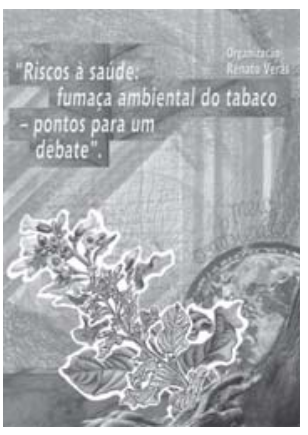

VERAS, Renato et al. (Org). Riscos à saúde: fumaça ambiental do tabaco - pontos para um debate. Rio de Janeiro: EdUerj; Unati, 2010. 66p.
$R$ iscos à saúde: fumaça ambiental do tabaco - pontos para um debate apresenta um conjunto de textos sobre tabagismo. ${ }^{1}$ Publicado pela Universidade Aberta da Terceira Idade (Unati) e pelo Instituto de Medicina Social, ambos da Universidade do Estado do Rio de Janeiro (Uerj), é fruto de um debate sobre os riscos à saúde derivados da fumaça ambiental do tabaco e o processo de progressiva interdição do hábito de fumar em áreas públicas, definido pela legislação brasileira. Produzida em três diferentes idiomas (português, inglês e francês), a coletânea é formada por textos escritos por professores do Instituto e por alguns profissionais com trabalhos relacionados ao tema. Com exceção do trabalho do epidemiólogo Geoffrey C. Kabat, e dos comentários elaborados por Lucien Sfez e por Renato Veras, todos os outros apresentam uma visão crítica à política antitabagista do governo brasileiro. Na verdade, ao ler a publicação fica-se com a impressão de que seu principal objetivo é a manifestação dessa crítica. Até aí nada de mais, mas é importante observar que, na pressa de criticar o que para muitos dos autores é um processo de exclusão e marginalização dos fumantes, diversas questões são distorcidas ou apresentadas de forma truncada ou panfletária. Apesar disso, a coletânea tem o mérito de trazer a público um tema polêmico sob uma perspectiva diferenciada.

Os três primeiros artigos, escritos respectivamente pelos sociólogos Luiz Antônio Castro Santos; Nelson F. de Barros e pelo professor e psicanalista Joel Birman, postulam que as ações antitabagistas hoje em voga estão transformando o ato de fumar em comportamento desviante e gerando um clima de perseguição aos fumantes. ${ }^{2}$ De forma geral, argumentam que o processo de exclusão social do fumante, a partir da lógica de temperança americana, estaria cada vez mais se expandindo no mundo ocidental, em consonância com o processo de ampliação das medidas de saúde reguladoras, embasadas em saberes epidemiológicos dominados pela noção absolutizada de risco. Castro Santos termina seu texto conclamando a sociologia à defesa das prerrogativas individuais - chave para a manutenção dos direitos coletivos - e à necessidade de avaliação dos efeitos inesperados desse processo que, a seu ver, caminha a passos largos em direção à violência e exclusão.

Para esses autores, a ação antitabagista estaria transformando os fumantes em verdadeiros párias da sociedade, versão moderna dos leprosos da Idade Média. Acredito que essa imagem, 
também utilizada em outros textos da coletânea, embora tenha uma grande força simbólica, não seja adequada ao processo de exclusão do tabagismo hoje em curso. O leproso do medievo, assim como o portador de outras doenças estigmatizadas, traziam em seu corpo a fonte do estigma que os vitimava. Estavam presos a esse signo de forma indelével, misturando a ele sua própria identidade. Excetuando exageros ${ }^{3}$, a intolerância discutida na obra em questão refere-se especificamente ao uso do tabaco, aos males que ele pode gerar aos seus consumidores e à inconveniência que ele impõe aos que estão próximo. Fumantes, em geral, só são tratados de forma diferenciada quando estão fazendo uso do tabaco. A não diferenciação entre a intolerância social a um determinado hábito e o preconceito contra pessoas que padecem de um mal específico esconde um aspecto importante da discussão: a inadequação do fumo a determinados ambiente se relaciona não a um processo social de exclusão de grupos ou pessoas, mas, ao contrário, ao processo de ampliação dos direitos individuais dos que acham a convivência forçada com a fumaça um aspecto inconveniente.

Alguns textos também enfatizam que a ações contra o tabaco estariam prejudicando uma forma de sociabilidade importante, caracterizada nos encontros regados a cigarros nos bares e cafés. Seus autores esquecem que a forma de utilização do fumo nas sociedades ocidentais modernas é um fenômeno recente, construído pelas grandes empresas americanas e inglesas de tabaco. $\mathrm{O}$ uso do fumo, inicialmente feito de forma ritual, difundiu-se somente a partir do século XIX, período em que seu consumo dava-se de formas distintas e menos frequentes. Apenas com a forte propaganda elaborada pelas grandes indústrias de produção de cigarros manufaturados seu uso de forma compulsiva passou a ser incorporado pelas sociedades. Essas mesmas companhias empregaram cifras gigantescas em campanhas publicitárias que acabaram por vincular o uso do cigarro a formas de sociabilidade há muito existentes e que dele prescindem.

O texto de Castro Santos, assim como o escrito pelo antropólogo Sérgio Carrara em coautoria com o médico Josué Laguardia e o de autoria do epidemiólogo Geoffrey Kabat afirmam que as pesquisas que procuram mostrar que o fumo passivo é prejudicial à saúde são insuficientes e controversas. Para Castro Santos não existem evidências seguras sobre os malefícios da fumaça ambiental do tabaco. Seu principal argumento repousa na impossibilidade de medir a intensidade da exposição à fumaça e a potencialidade do risco que essa exposição pode acarretar. Os dois primeiros textos sublinham que o interesse em mostrar os malefícios do fumo gera verdadeiro 'macarthismo científico', fazendo com que trabalhos que mostram a gradação das consequências do hábito de fumar em relação à quantidade de cigarros consumidos ou que afirmam que os efeitos da fumaça do tabaco não são tão intensos sejam deixados de lado ou se transformem em alvos de ataques. No entender de seus autores, da mesma forma que as empresas de tabaco procuraram elaborar estudos que desqualificassem os argumentos que uniam câncer e tabaco, as pesquisas sobre malefícios do fumo passivo - normalmente patrocinadas por centros de controle do tabaco, agências governamentais e ONGs contrárias ao uso do tabaco - muitas vezes são elaboradas a partir de metodologias inadequadas, resultando em resultados parciais ajustados somente à lógica de seus produtores. 
Castro Santos também se detém na crítica à Convenção-Quadro para o Controle do Tabaco. A seu ver, esse acordo é um instrumento que busca a erradicação completa das plantações de tabaco, sem levar em conta que tal medida é contrária aos pequenos produtores que há gerações plantam fumo como forma de sobrevivência. No seu entender: "A Convenção-Quadro deverá ser reavaliada e alterada em seus objetivos rígidos e socialmente insustentáveis" (p.14).

Essa visão é bastante distorcida. A Convenção-Quadro para o Controle do Tabaco é um acordo internacional de saúde pública, patrocinado pela Organização das Nações Unidas, visando à diminuição global do tabagismo. Sua meta é ser uma referência para os paísesmembros, em relação ao controle do tabaco. Em seus diversos capítulos são propostas medidas relacionadas à normatização da propaganda e patrocínio; mensagens de advertência em embalagens dos produtos; educação e conscientização da população; proibição de fumar em ambientes fechados; controle do mercado ilegal de cigarros; regulação dos conteúdos dos produtos de tabaco; tratamento dos dependentes de nicotina; cooperação técnica e científica, educacional e sanitária. ${ }^{4}$ No entanto, em nenhum de seus artigos é postulada a erradicação das culturas de fumo dos países-membros ou obrigações suprimindo o direito dos produtores de tabaco de permanecerem em seus cultivos.

As negociações para a sua implantação se iniciaram em 1999, tendo o Brasil como um de seus principais articuladores. No entanto, em virtude das pressões das companhias produtoras de tabaco, somente em 2005 o Brasil se tornou signatário efetivo do acordo. A resistência das companhias produtoras de tabaco a possível intensificação de medidas normatizadoras de suas atividades só foi vencida no Congresso, quando a então ministra da Casa Civil da Presidência da República, Dilma Roussef, enviou à comissão responsável pela avaliação do acordo um documento propondo duas medidas adicionais para a proteção dos fumicultores. A primeira previu a inserção de uma declaração de interpretação de dispositivos ao texto da Convenção, ressaltando a não proibição do cultivo ou a restrição a políticas nacionais de apoio aos agricultores que se dedicam a essa atividade; a segunda previa o lançamento de um Programa de Apoio à Diversificação Produtiva das Áreas Cultivadas com Fumo, com foco no financiamento, acesso à tecnologia, agregação de valor à produção local e garantia de comercialização. ${ }^{5}$

De forma contrária ao que supõe Castro Santos, a Convenção-Quadro para o Controle do Tabaco não se apresenta no Brasil como um imperativo para uma autoritária erradicação das culturas de tabaco no país; ela busca possibilitar ao pequeno produtor o cultivo de diferentes culturas, de forma menos agressiva a sua saúde e também lucrativa. Não podemos esquecer que o Brasil é o maior exportador de folhas de tabaco e segundo maior produtor de fumo do mundo (Cavalcante, 2005), e que a produção do fumo utiliza métodos extremamente agressivos, em especial o emprego extensivo de agrotóxicos que provocam intoxicação e outros riscos à saúde dos pequenos produtores. ${ }^{6}$ A cultura do tabaco se intensificou no país a partir dos anos 1910 quando a British American Tobacco criou o 'sistema integrado de produção de fumo', que lhe garante o controle de todo o processo de produção e comercialização do produto. ${ }^{7}$ Com o declínio da utilização do tabaco nos EUA, a partir do último quartel do século XX, a produção em países em desenvolvimento tornou-se estratégica para as multinacionais produtoras de cigarros. Os grupos que buscavam 
impedir a adesão à Convenção-Quadro tinham como seus principais protagonistas associações que, embora se apresentassem como defensoras dos pequenos produtores, mantinham relações com as grandes indústrias de tabaco internacionais. ${ }^{8}$

Seguindo os estudos que postulam que as ações comunitárias contra possíveis ameaças a modos de vida estabelecidos podem vir a se transformar em uma ideologia pública de largo alcance, Castro Santos sugere que, da mesma forma que as ações de comunidades americanas contra o consumo de bebidas alcoólicas, ocorridas no final do século XIX, se relacionam a posterior promulgação da lei seca nos anos 1920, o processo de exclusão dos fumantes das áreas públicas, ocorrido a partir do final do século $\mathrm{XX}$, deve ser visto como uma expressão de um novo clima de temperança, agora fortalecido pelos conhecimentos oriundos das ciências médicas, em especial da epidemiologia.

Na mesma linha, Carrara e Laguardia, e Birman afirmam a existência de uma nova cruzada moral empreendida em nome da saúde pública. Este último propõe que a interdição de fumar segue diferentes padrões nas diversas formações sociais, se relacionando a códigos culturais, religiosos e sociais diferenciados. No caso do Brasil, o autor acredita haver um caráter draconiano na lei que impede o fumo em lugares públicos. Comparando-a com a legislação espanhola e argentina, que permitem o uso do fumo em lugares semifechados, Birman propõe que a rigidez da lei brasileira se insere na tradição estadunidense de moral protestante, que caracteriza os fumantes como impuros.

Em termos de legislação as informações que dão base ao argumento de Birman encontram-se desatualizadas. Em Cuba, no Panamá e no Uruguai é proibido fumar em lugares fechados. ${ }^{9} \mathrm{Na}$ Europa, França, Dinamarca, Suécia e Finlândia e Portugal também proibiram o fumo em lugares fechados. ${ }^{10} \mathrm{Na}$ Suécia é proibido fumar em bares e restaurantes. $\mathrm{Na}$ Holanda, pasmem, o fumo é proibido nas estações de trem e outros lugares públicos, restaurantes incluídos. ${ }^{11} \mathrm{Na}$ Irlanda, desde 2004, é proibido fumar mesmo nos famosos pubs. ${ }^{12}$ Contrariando o que imagina o autor, na Espanha, a partir do início do ano, uma nova lei proibiu o fumo nos lugares públicos, como bares, restaurantes e aeroportos e até em locais de ar livre como nas áreas de lazer infantil. ${ }^{13}$ Como fica claro, esse processo pouco se relaciona à moral protestante.

A discussão inicial de Birman serve de base para a sua argumentação. Partindo da assertiva de Freud de que o consumo de algum tipo de excitante é uma das formas de o sujeito lidar com o mal-estar presente na sociedade (p.28), ele analisa as possibilidades de controle dessa busca de excitação, mostrando que, no limite, a completa normatização dessas válvulas de escape seria uma utopia. Sua bem cuidada argumentação tem o objetivo de justificar a ideia de que a maior repressão ao fumo está levando ao incremento do consumo de bebidas alcoólicas, de outras drogas ilícitas e a excessos na alimentação dos jovens. Partindo de uma observação antropológica um tanto heterodoxa, que mistura a observação do consumo de cerveja por jovens em bares próximos à janela de sua casa, a uma pesquisa publicada no jornal $O$ Globo, que afirma que hoje se bebe mais do que em décadas passadas, ele assevera que "a juventude procurou uma derivação para isso [a interdição do fumo], pelas bebidas alcoólicas, pelas drogas estimulantes e até mesmo pela comida. Portanto, em nome do imperativo da saúde, o fumo foi substituído pelo álcool, pelas drogas e pela comida" (p.27). Essa conclusão parece-me apressada e com pouca 
densidade analítica. É importante levar em conta que os dados apresentados na pesquisa cobrem somente o período 2006-2009, um intervalo muito pequeno para a elaboração de conclusões mais abrangentes. ${ }^{14}$ Além disso, apesar de o consumo de bebida e outras drogas estar aumentando, não existe um indicativo seguro de sua relação com a diminuição do uso de tabaco. ${ }^{15}$

O último capítulo da coletânea apresenta um texto mais requintado, que trabalha a noção de risco e sua utilização na saúde pública. Castro Santos e a antropóloga Alba Zaluar postulam a necessidade de uma aproximação simétrica de sociologia e epidemiologia, acreditando que essa convergência possa gerar uma nova visão de saúde pública que incorpore o risco não somente em sua feição epidemiológica, mas considerando os aspectos sociais e as subjetividades a ele relacionados. Fundamentados em uma larga bibliografia sobre o tema, eles questionam a supremacia da concepção epidemiológica do risco em saúde pública que, em sua inflexibilidade, avalia sob o mesmo prisma diferentes culturas e valores, que a partir de vivências diferenciadas negociam a saúde de maneiras distintas. Essa visão epidemiológica do risco acaba por cercear a liberdade de indivíduos e coletividades de avaliar as incertezas cotidianas de suas vidas e decidir livremente como lidar com elas.

Para transformar esse contexto, os autores tomam de empréstimo a concepção de Bruno Latour (2000) sobre a forma adequada de os governos lidarem com a noção de risco. Para o sociólogo francês, a ciência, como uma atividade coletiva, envolta em incertezas e controvérsias a todo momento negociadas, não deve ser a única fonte para a tomada de decisões. Elas devem levar em conta os diversos interlocutores da atividade científica, com os quais também se faz necessário o entendimento, e o respeito à voz do outro. Assim, os governos e seus órgãos de saúde pública devem ser mais cautelosos em suas medidas normativas, fazendo-as contemplarem as indeterminações da vida cotidiana e do conhecimento científico.

Como indiquei no início do texto, a maior parte das análises da coletânea tem como pano de fundo a noção de que as leis antifumo brasileiras são um aparato autoritário, fundado na noção de risco, se caracterizando como um impedimento ao cidadão de viver a sua liberdade de escolha. Gostaria de opor dois comentários a essa argumentação. O primeiro diz respeito à liberdade individual em relação ao uso do tabaco. Mesmo aceitando a precariedade do conhecimento sobre os riscos do fumo passivo, não existem dúvidas no campo da ciência sobre os riscos em relação à saúde dos fumantes. A noção de que o fumante deveria ter a liberdade para se submeter a esse risco sem constrangimentos legais deixa de lado fatores muito mais violentos do que as interdições jurídicas que os impedem de fazer uso do tabaco em determinados lugares. Não podemos esquecer que a nicotina é uma substância que produz dependência, transformando uma parte dos fumantes regulares em escravos do produto, em vez de consumidores racionais, que dele fazem uso somente para o seu lazer.

Não é necessário ultrapassar os limites da publicação examinada para avaliar esse aspecto, pois as informações apresentadas no texto em que o epidemiologista Geoffrey Kabat discute as posições de Castro Santos são precisas ao mostrar a impossibilidade dessa livre escolha. Diz ele: "A maioria das pessoas começa a fumar em uma idade em que ainda não estão totalmente desenvolvidas neurologicamente, e em que pensam que vão viver para sempre. 
A decisão de fumar entre os jovens é muitíssimo influenciada pelo exemplo dos pais fumantes, pela pressão dos colegas e pela propaganda das companhias de tabaco etc. O fumo é altamente viciante em alguns fumantes, e para esses pode ser virtualmente impossível parar" (p.32). Além disso, é impossível pensar na possibilidade de livre avaliação do risco do consumo de tabaco numa sociedade com baixos níveis de educação e informação científica e com um mercado de cigarros dominado por empresas gigantescas, detentoras de poderes fortíssimos que usam dos mecanismos mais astuciosos - do marketing agressivo à compra de políticos - para manter seus mercados consumidores.

O segundo comentário também diz respeito à liberdade, só que nesse caso à liberdade de escolha de se conviver ou não com uma prática suspeita de trazer prejuízos à saúde. Se o fumante deve ter o direito de administrar o risco de sua prática, certamente o não fumante tem o mesmo direito de fazê-lo. Retorno às palavras de Kabat para avaliar essa questão: "por muito tempo o 'direito a fumar' foi tomado como normal, enquanto levaramse décadas para que o princípio de que os não fumantes não deveriam respirar a fumaça do tabaco se estabelecesse. O que quer que pensem sobre a letalidade da fumaça ambiental do tabaco, me parece ser um grande passo em direção a uma sociedade civilizada não ter que ficar na fila de um correio mal ventilado atrás de alguém fumando um cigarro ou charuto" (p.36).

\section{NOTAS}

${ }^{1}$ Agradeço a Tiago Alves Jaques as charges e importantes informações que foram base para esta resenha. 2 Os artigos têm os seguintes títulos: "Em defesa dos fumantes"; "Sobre humilhados visíveis e invisíveis: um sonho lúcido de realidade"; "Sobre o risco e a periculosidade social: a lei antifumo em questão".

${ }^{3}$ Refiro-me a práticas como as que impedem fumantes de alugar determinados imóveis, que ocorrem em algumas regiões dos Estados Unidos.

${ }^{4}$ O texto completo da Convenção-Quadro para o Controle do Tabaco pode ser encontrado em: http:/ /www2.mre.gov.br/dai/m_5658_2006.htm.

${ }^{5}$ Sobre a Convenção-Quadro de Controle do Tabaco ver, Jaques, 2010.

${ }^{6}$ A própria folha do tabaco também é tóxica, seu manuseio provoca a doença da folha verde, muito comum entre os cultivadores de fumo. Outro aspecto importante diz respeito ao fato de a cultura do tabaco ser extremamente agressiva ao meio ambiente. Para mais informações sobre esse tema ver, Boeira, Giuvant, 2003.

${ }^{7}$ Nesse sistema os colonos são dependentes da agroindústria do tabaco, posto que as empresas fornecem sementes e fertilizantes como forma de adiantamento, financiam a construção das estufas necessárias à cultura e fornecem assistência técnica aos agricultores, garantindo a sua submissão aos métodos de produção por elas definidos. No sentido contrário, as agroindústrias têm a exclusividade da compra integral da produção (Boeira, Guivant, 2003, p.50).

${ }^{8}$ A Associação de Fumicultores do Brasil (Afubra), instituição que mais atuou na luta contra a aprovação da Convenção-Quadro, por exemplo, é um órgão vinculado à Associação Internacional dos Produtores de Tabaco, considerada uma instituição de fachada, criada para defender os interesses das indústrias de cigarros (Brasil, 2004). Para fazer essa afirmação o Inca se respalda em documentos confidenciais das companhias de cigarro, atualmente disponíveis em: www.library.ucsf.edu/tobacco.

${ }^{9}$ Para uma rápida observação da legislação antifumo em diversos países ver o site da Tobacco Control Laws http://tobaccocontrollaws.saforian.com/ ou o verbete "List of smoking bans" da Wikipedia (http:/ /en.wikipedia.org/wiki/List_of_smoking_bans), em que é possível encontrar as fontes para informações mais fidedignas. Sobre a legislação antitabaco em Cuba ver, Suarez Lugo, Caraballoso Hernandez, Rodriguez Cuelez, 2008. 
${ }^{10}$ A informação sobre Portugal foi encontrada no jornal Mundo Lusíadas, 5 jan. 2008.

${ }^{11}$ A partir de 2010 o fumo passou a ser permitido em espaços específicos dos aeroportos e em bares em que o proprietário é o único trabalhador (Belfast Telegraph, Nov. 4, 2010).

12 Ver, BBC, Mar. 29, 2004.

${ }^{13}$ Informações específicas sobre a Espanha encontram-se no jornal El Pais, 13 fev. 2011.

${ }^{14}$ A apresentação da pesquisa Vigitel - base para a matéria de $O$ Globo - traz a seguinte informação: "Os resultados apresentados nesta seção devem ser vistos com cautela em face de que o exíguo período de tempo que separa os inquéritos pode não ter sido suficiente para produzir variações temporais estatisticamente detectáveis" (Ministério da Saúde, 2010, p.123).

15 Para muitos profissionais de saúde, o aumento do consumo de bebidas alcoólicas se relaciona principalmente à falta de normatização da propaganda do produto que, de forma, abusiva estimula os jovens ao consumo, e a diminuição ou cessação dessa prática deve diminuir os índices de consumo. Ver, Pinsky, Jundi, 2008.

\section{REFERÊNCIAS}

BBC.

All eyes on Ireland's smoking ban. $B B C$

News, London. Health. Available at:

http://news.bbc.co.uk/2/hi/health/3565899.stm. Access on: Jun. 6, 2012. Mar. 29, 2004.

BELFAST TELEGRAPH.

Smoking ban U-turn by Dutch government. Belfast Telegraph, Belfast. World News.

Available at:

http://www.belfasttelegraph.co.uk/news/worldnews/smoking-ban-uturn-by-dutch-

government-14995132.html. Access on: Jun. 6, 2012. Nov. 4, 2010.

BOEIRA, Sérgio Luíz; GIUVANT, Julia Silvia. Indústria de tabaco, tabagismo e meio ambiente: as redes ante os riscos. Cadernos de Ciência \& Tecnologia, Brasília, v.20, n.1, p.45-78. 2003.

BRASIL.

Ministério da Saúde. Secretaria de Vigilância em Saúde. Secretaria de Gestão Estratégica e Participativa. Vigitel Brasil 2009: vigilância de fatores de risco e proteção para doenças crônicas por inquérito telefônico. Brasília: Ministério da Saúde. 2010.

BRASIL.

Ministério da Saúde. Instituto Nacional de Câncer. Ação Global para o Controle do Tabaco: primeiro tratado internacional de saúde pública. 2004.

CAVALCANTE, Tania.

O controle do tabagismo no Brasil: avanços e desafios. Revista de Psiquiatria Clínica, São Paulo, v.32, n.5, p.283-300. 2005.
EL PAIS.

La prohibición de fumar se amplía por primera vez a espacios abiertos. El Pais, Madrid.

Sociedad. Disponible en: http://elpais.com/ diario/2010/10/20/sociedad/

1287525603_850215.html. Acceso en: 6 jun. 2012. 13 feb. 2011.

JAQUES, Tiago Alves.

Impasses e estratégias: Convenção-Quadro e Controle do tabagismo no Brasil (1986-2005). Dissertação (Mestrado) - Casa de Oswaldo Cruz, Fundação Oswaldo Cruz, Rio de Janeiro. 2010.

LATOUR, Bruno.

$\mathrm{Du}$ principe de précaution au principe $d u$ bon gouvernement: vers de nouvelles règles de la méthode expérimentale. Disponível em: http:// www.bruno-latour.fr/poparticles/poparticle/ p088.html. Acesso em: 12 abr. 2011. 2000.

MUNDO LUSÍADA.

Mundo Lusíada, São Paulo. Disponível em: http://www.mundolusiada.com.br/ ACONTECE/acon383_jan08.html. Acesso em: 12 abr. 2011.5 jan. 2008.

PINSKY, Ilana; JUNDI, Sami. O impacto da publicidade de bebidas alcoólicas sobre o consumo entre jovens: revisão da literatura internacional. Revista Brasileira de Psiquiatria, São Paulo, v.30, n.4, p.362-374. 2008.

SUAREZ LUGO, Nery; CARABALLOSO HERNANDEZ, Magali; RODRIGUEZ CUELEZ, Delvys Manuel.

Smoking control legislation in Cuba. Revista Cubana de Salud Pública, La Habana, v.34 n.3, p.1-12. 2008. 